\title{
Concurrent Validation and Reference Values of Gluteus Medius Clinical Test
}

\author{
Amanda S S Teixeira', Paula L Silva', Sabrina P Cintra', Fernanda Viegas', Luciana D Mendonça ${ }^{3}$, Natália F N \\ Bittencourt ${ }^{4}$ \\ 1 School of Physical Education, Physiotherapy and Occupational Therapy, Federal University of Minas Gerais, ${ }^{2}$ Center for Cognition, Action, \& \\ Perception, Department of Psychology, Universtity of Cincinnati, 3 Physiotherapy Department, Faculty of Biological and Health Sciences, Federal \\ University of Vales do Jequitinhonha and Mucuri, ${ }^{4}$ Head of the Physical Therapy Department, Minas Tenis Clube \\ Keywords: endurance, gluteus medius, injury, movement system, physiotherapy, strength
}

https://doi.org/10.26603/001c.21477

\section{International Journal of Sports Physical Therapy}

Vol. 16, Issue 2, 2021

\section{Context}

The hip abductor muscles, mainly the gluteus medius, are responsible for controlling hip adduction in a closed kinetic chain. Frontal plane knee alignment, assessed during functional activities such squatting, jumping and running, may overload joint structures, like the anterior cruciate ligament and patellofemoral joint. The hand-held dynamometer is reliable and effective for testing the muscular strength of the hip abductors.

\section{Objectives}

(1) To assess the concurrent validity between the gluteus medius clinical test and a maximum isometric force test of the hip abductors using the hand-held dynamometer; (2) to determine the intra and inter-examiner reliability for the application of the gluteus medius clinical test; and (3) to describe reference values of gluteus medius clinical test on a population of youth athletes.

\section{Design}

Cross-sectional.

\section{Methods}

Thirty healthy individuals were recruited for validity and reliability testing. On the first day, participants performed the maximal isometric test of the hip abductors, measured via hand-held dynamometry. On the following week, the gluteus medius clinical test was performed. Intraclass correlation coefficients $\left(\mathrm{ICC}_{2,2}\right)$ were computed for the reliability analysis, with a $95 \%$ confidence interval. To generate reference values, the gluteus medius clinical test was performed on 273 athletes.

\section{Results}

The results of this study indicated a weak positive correlation $(r=0.436, p=0.001)$ between tests, which indicates that they examine different domains of gluteus medius muscle function, likely endurance and muscle strength. The magnitude of computed ICCs $(>0.95)$ indicates excellent intra- and inter-examiner reliability.

\section{Conclusion}

The findings of the current study indicate that the gluteus medius clinical test is reliable and examines a domain of muscular function not fully captured by HHD. The clinical test developed in this study is low-cost and can be included for gluteus medius assessment.

\footnotetext{
a Corresponding Author:

Luciana D. Mendonça

Rodovia MGT 367 - Km 583, 5000 - Diamantina/MG.

CEP: 39100-000. Telephone: +55-31-98888-2945.

E-mail: lucianademichelis@yahoo.com.br
} 


\section{Level of evidence}

Level 3.

\section{INTRODUCTION}

The hip abductor muscles, mainly the gluteus medius (GM), are responsible for controlling hip adduction in closed kinetic chain, ${ }^{1}$ and are associated with preventing dynamic knee valgus during the single leg squat. ${ }^{2}$ Dynamic knee valgus can result in injuries, such as anterior cruciate ligament (ACL) tears and patellofemoral joint pain (PFJP). ${ }^{3}$ Diminished GM volume has been found in individuals with PFJP compared to control participants. ${ }^{4}$ The primary hip abductors are the GM, the gluteus maximus and the tensor of the fascia lata. The gluteus medius is the largest abductor, representing approximately $60 \%$ of the transverse area of this muscle group. ${ }^{5}$ In addition, the posterior GM fibers also produce lateral hip rotation, which helps to reduce excessive medial rotation and influence dynamic knee valgus in an attempt to maintain dynamic hip stability during functional activities. ${ }^{6}$ Studies have shown that maintaining pelvic stabilization and good knee kinematics require adequate $\mathrm{GM}$ action. $^{6}$

Muscle fatigue is important factor to consider during squatting and jumping. Fatigue may be associated with lower limb misalignment, especially in long-duration sports, such as running. ${ }^{7}$ Geiser et al. ${ }^{8}$ showed that hip abductor fatigue increases the dynamic valgus during jumps, which may increase risk of knee injuries. Therefore, good muscular function of the GM is necessary, considering both strength and endurance.

Objective information about muscular strength is clinically relevant because it supports formulation of treatment plan and selection of preventive interventions. One of the devices used to measure muscle strength is the hand-held dynamometer, which has concurrent validity with the isokinetic dynamometer, considered the gold standard. ${ }^{9}$ According to Jaramillo et al. ${ }^{10}$ the hand-held dynamometer is a reliable tool for testing hip abductor strength. However, the practicality and utility of this tool has been questioned due to cost $(\sim \$ 1,000.00$ USD) and the requirement for yearly calibration. ${ }^{9}$ Additionally, a recent meta-analysis describing risk factors for patellofemoral pain has shown limited evidence related to hip strength measured using the handheld dynamometer. Neal et al argued that isometric muscle testing may not be sensitive enough to identify individuals at risk of PFJP. ${ }^{11}$ Considering these limitations of the handheld dynamometer and the requirement to quantify GM muscle function in clinical practice, the purposes of the present study were: (1) to perform concurrent validation of the GM Clinical Test with the isometric torque test using the hand-held dynamometer; (2) to determine the intra and inter-examiner reliability of GM Clinical Test; and (3) to describe reference values of GM Clinical Test in a population of youth athletes.

\section{METHODS}

\section{STUDY DESIGN}

The present study was a cross-sectional study to determine concurrent validation, reliability, and reference values for the GM clinical test.

\section{PARTICIPANTS}

For examination of concurrent validity and reliability, 30 participants (13 men and 17 women) were selected. The mean age was 36.4 years $( \pm 16.6)$ and body mass was 70.43 $\mathrm{kg}( \pm 15.02)$. The inclusion criteria were: (a) absence of pain or history of injury in lower limbs; and (b) no history of surgery in the lower limbs in the prior six months. Participants who reported pain during the application of the tests were excluded from this study.

For reference values, 273 athletes (81 women and 192 men) from a sports club were selected during the pre-season assessment with a mean age of 14.6 years $( \pm 2.1)$, height $1.75 \mathrm{~m}( \pm 1.4)$ and body mass of $65.1 \mathrm{~kg}( \pm 15.7)$. The athletes were part of the volleyball, basketball and judo teams. The same examiners from the reliability study performed the clinical gluteal endurance test on athletes to ensure the required standardization for reference values.

\section{PROCEDURES}

The present study was approved by the Ethical Committee of the Universidade Federal de Minas Gerais (ETIC No. 493/ 2009) and all individuals who agreed to participate in the study signed the informed consent. The participants were personally invited by researchers and through social media to participate in the present study.

The hip abductor isometric torque was measured using a hand-held dynamometer (microFET2, Hoggan Health Industries, Inc., West Jordan, UT), considered a valid and reliable instrument for measuring muscle strength. ${ }^{10}$ The subject was positioned in the side lying position with the upper limbs crossed in front of the trunk, aligned scapular and pelvic girdles, the hip and knee of the contralateral lower limb to the limb tested were flexed, and the tested lower limb was positioned with the hip in neutral in the sagittal plane and the knee extended (Figure 1). The hand-held dynamometer was positioned $5 \mathrm{~cm}$ above the knee joint interline ${ }^{12}$ and attached to a Velcro ${ }^{\circledR}$ strap that allowed hip abduction in the frontal plane.

The subject was asked to perform hip abduction until the movement was restricted by Velcro ${ }^{\circledR}$, and maintained maximal isometric contraction for five seconds with standardized verbal command. This procedure was performed three times in each lower limb, with a 15 second interval between measurements. ${ }^{12}$ The abductor torque was calculated by the average of three values measured, multiplied by a measurement of the distance between the greater trochanter of the femur to $5 \mathrm{~cm}$ above the lateral knee joint line. The torque value was divided by body mass to obtain normalized data $(\mathrm{Nm} / \mathrm{kg})$. Intra- and inter-examiner reliability analysis was performed on 30 participants, with a seven-day interval between the assessments.

The GM Clinical Test was performed in the same position as the torque test. The individual was in the side lying po- 
sition with the upper limbs crossed in front of the trunk, aligned scapular and pelvic girdles, flexed contralateral hip and knee, and the limb being tested with an extended hip and knee (Figure 2). Widler et al. ${ }^{13}$ reported that this position is the most valid and reliable for hip abductor strength evaluation, verified by the GM electromyographic activity. The abduction movement of the evaluated lower limb was performed without any external resistance.

The individual was asked to perform the hip abduction movement maintaining the initial position, and the number of repetitions was not previously suggested to the participants, although it was standardized to a maximum of 15 repetitions. The range of motion was not previously informed either, but the examiners asked the participants to avoid changing the initial position of pelvis and trunk. The time to accomplish this test was not controlled. The examiner assessed for possible qualitative movement compensations: (I) hip flexion; (II) trunk rotation; and (III) pelvic elevation. The test was interrupted, through verbal command of the examiner, when there was some compensation among those mentioned above. The examiner registered the number of repetitions corresponding to the test interruption. The test was interrupted by verbal command at repetition 15 when the participant did not perform any compensation.

\section{STATISTICAL ANALYSES}

Mean and standard deviation for the dominant and nondominant limbs was computed to normalize the primary study variables: body-mass normalized abductor torque and number of repetitions of GM Clinical Test. Concurrent validity between tests was examined using Pearson correlation coefficient and simple linear regression to obtain the coefficient of determination $\left(\mathrm{r}^{2}\right)$. To determine GM Clinical Test intra- and inter-reliability, ICC $_{2,2}$ with a 95\% confidence interval was used.

\section{RESULTS}

\section{CONCURRENT VALIDATION AND RELIABILITY STUDY}

The values obtained for the concurrent validity and reliability analysis were from both limbs from the 30 participants. The mean normalized torque value of the hip abductors measured by HHD was $1.2( \pm 0.39) \mathrm{Nm} / \mathrm{kg}$, and the mean number of repetitions in the GM Clinical Test was 5.7 $( \pm 4.06)$ repetitions.

A significant weak correlation was observed between the hand-held dynamometer test for hip abductor torque and the GM Clinical Test $(r=0.436 ; p=0.001)$. Simple linear regression demonstrated a low coefficient of determination $\left(\mathrm{r}^{2}=0.19\right)$, which means that $19 \%$ of the hip abductor isometric torque variation is explained by the number of the clinical test repetitions. The intra-examiner reliability for the GM Clinical Test was high (Examiner 1=0.98; Examiner $2=0.96$ ), and the inter-rater reliability for the GM Clinical Test was also considered high (0.95) (Table 1).

\section{REFERENCE VALUES STUDY}

For the 273 youth athletes, the mean values found in the

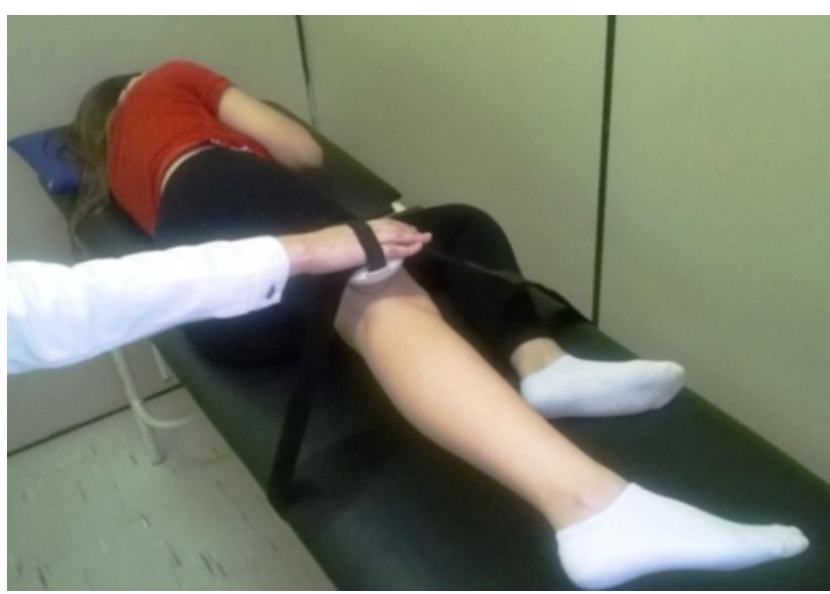

Figure 1: Position for the hand-held dynamometer test for hip abductor torque test.

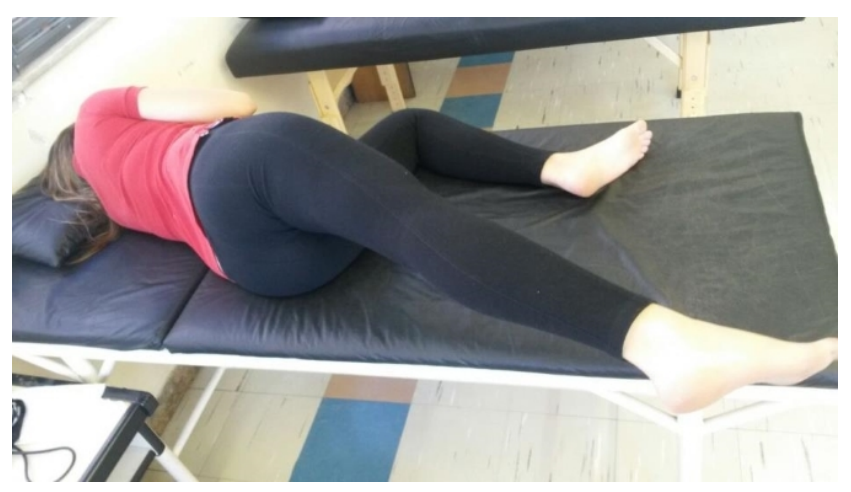

Figure 2: Participant position for GM Clinical Test.

Table 1: Intra-examiner and inter-examiner reliability for the GM Clinical Test

\begin{tabular}{ccc}
\hline & \multicolumn{2}{c}{ Intra-examiner reliability } \\
\hline Measures & ICC & Confidence Interval \\
$\mathrm{E}_{1}$ & 0.98 & $0.94-0.99$ \\
$\mathrm{E}_{2}$ & 0.96 & $0.90-0.99$ \\
\hline & Inter-examiner reliability \\
\hline Measures & ICC & Confidence Interval \\
$\mathrm{E}_{1} \times \mathrm{E}_{2}$ & 0.95 & $0.79-0.99$ \\
\hline
\end{tabular}

$\mathrm{E}_{1}=$ examiner $1 ; \mathrm{E}_{2}=$ examiner 2.

GM Clinical Test were $4.1( \pm 3.9)$ repetitions on the dominant limb (D) and $3.4( \pm 3.1)$ repetitions on the non-dominant limb (ND). In female athletes, the mean number of repetitions on the D limb was $4.1( \pm 4.9)$ and on the ND 3.4 $( \pm 3.3)$. In the male athletes, the mean number of repetitions on the D side was $3.6( \pm 5.0)$ and on the ND $2.9( \pm 3,1)$. The mean values in relation to sport participation are presented in Table 2. 
Table 2: Reference values of the GM Clinical Test (in number of repetitions). Data are presented as means (SD).

\begin{tabular}{|c|c|c|c|}
\hline & Volleyball & Basketball & Judo \\
\hline \multicolumn{4}{|c|}{ Dominant Side } \\
\hline Mean ( \pm SD) & $4.2( \pm 3.5)$ & $3.6( \pm 4.1)$ & $4.8( \pm 4.7)$ \\
\hline Minimum & 0 & 0 & 1 \\
\hline Maximum & 15 & 23 & 20 \\
\hline \multicolumn{4}{|c|}{ Non-dominant Side } \\
\hline Mean ( \pm SD) & $3.6( \pm 2.8)$ & $2.6( \pm 2.9)$ & $4.5( \pm 3.8)$ \\
\hline Minimum & 0 & 0 & 0 \\
\hline Maximum & 13 & 13 & 15 \\
\hline
\end{tabular}

\section{DISCUSSION}

The present study aimed to examine the concurrent validity between GM Clinical Test and hip abductors isometric torque test using the hand-held dynamometer, to determine intra- and inter-examiner reliability for both tests, and to describe reference values of clinical test in youth athletes. The results indicated a significant, but weak correlation between GM Clinical Test and hand-held dynamometer test $\left(r=0.436\right.$ and $\left.r^{2}=0.19\right)$. The reference values for clinical test were $4.1( \pm 3.9)$ repetitions on the $\mathrm{D}$ limb and $3.4( \pm 3.1)$ repetitions on the ND limb on average. The ICC values found in this study, above 0.95 , are indicative of excellent intra- and inter-examiner reliability. ${ }^{14}$ These findings allow physiotherapists to reproduce both of these testing methods in clinical practice, in order to quantitatively evaluate the strength and possibly muscular endurance of hip abductors.

The hand-held dynamometer is a valid and reliable tool used to quantify muscular strength, and is considered a practical instrument, due to its portability and size, compared to the gold standard, the isokinetic dynamometer. ${ }^{10}$ The hand-held dynamometer test for hip abductor strength is performed through maximum isometric contraction, where the muscle force corresponds to its maximum capacity to generate tension. In general, tests that use the HHD are less used in practice for prescription of exercises, due to the high cost of the instruments and difficulty of operation. ${ }^{15,16}$ Additionally, the majority of sports activities are dynamic in nature and isometric strength may not be the best way to assess muscle function in this context. ${ }^{17}$

On the other hand, the GM Clinical Test represents the ability to perform muscle contractions under submaximal loads. ${ }^{16}$ The muscular action tested by the two methods is likely different, testing two domains, strength and endurance. ${ }^{18}$ Both domains are important to prevent musculoskeletal injuries, to exercises prescription and to promote joint stability. ${ }^{19}$ Moreover, a recent study was designed to assess hamstring endurance in soccer athletes through the unilateral hip bridge test. As with the present study, the repetitions were interrupted if there was a change in movement pattern and performing less than 22 repetitions was associated with hamstring strain. ${ }^{20}$ Therefore, the GM Clinical Test could be used complementary to the hand-held dynamometer or when it is not possible to purchase a HHD in low-income sports context.

The hip abductor isometric torque and the GM Clinical Test were significantly correlated, although only at $r=$ 0.436 . According to Portney et al., ${ }^{21}$ values between $r=0.25$ and $r=0.50$ represent a weak correlation. Correlation coefficients between clinical measures ranging from 0.57 to 0.78 are considered appropriate values for clinical practice, meaning that these tests cannot be used interchangeably. ${ }^{22}$ However, the isometric hip abductor test and the GM Clinical Test showed high values of intra-examiner reliability (Table 1), since values above 0.90 are indicative of excellent reliability. ${ }^{16}$ These findings demonstrate that both tests can be reliably replicated in clinical practice for physical therapy evaluation and re-evaluation of the different strength and endurance domains of the hip abductors.

Muscle endurance also is important to preserve joint stability during sports movement. When a muscle fatigues, there is overload in the passive elements, such as capsules and ligaments, as well as movement pattern changes. ${ }^{23} \mathrm{Fa}$ tigue may be associated with injury risk, because its influences the lower limbs' alignment. For example, muscle endurance deficits may be an important contributing factor in the development of PFJS. ${ }^{24}$ Van Cant et al demonstrated an important endurance deficit of hip abductor muscles in patients diagnosed with PFJS. Recent authors have demonstrated a correlation between low endurance of GM and excessive dynamic valgus, ${ }^{25}$ and it is known that fatigue may predispose athletes to knee injuries due to changes in alignment and dynamic knee joint stability. ${ }^{26}$ Lower limb injuries, such as ACL rupture during landing from an uncontrolled jump, often occur during the last 15 minutes of the first half and in the last 30 minutes of the second half in a football match. ${ }^{7}$ Additionally, the American College of Sports Medicine recommends that endurance must be included in a training program, as well as muscle strength exercises. ${ }^{27}$ Considering the influence of fatigue on sports injuries, practitioners involved in prevention and rehabilitation of musculoskeletal injuries should consider a periodic assessment of muscle endurance in order to protect the athlete in sport settings. ${ }^{29}$

The reference data from the present study demonstrated that youth athletes participating in volleyball, basketball and judo, on average, can perform four repetitions of hip abduction without movement compensation. Until now, studies using the same methodology are not available. Therefore, the authors cannot compare the present data 
for youth athletes with other studies. However, a study by Freckleton et $\mathrm{al}^{19}$ evaluated hamstring endurance in young soccer athletes through the unilateral bridge test, and the athletes with a previous history of hamstring strain performed on average, 22 repetitions, while the uninjured athletes did 26 repetitions. Despite being different tests, the parameter of muscular endurance was evaluated in the two studies and the results of the present study demonstrate that athletes are likely to have low GM endurance.

Some limitations of the study should be considered. The hand-held dynamometer test involves all the abductor muscles of the hip, GM, gluteus minimus, tensor fascia lata, and sartorius, as demonstrated by Widler et $\mathrm{al}^{13}$ in an electromyographic study. In contrast, during the GM Clinical Test, the evaluation of the GM was prioritized, by maintaining the hip extension position of the lower limb tested. Therefore, the clinical test developed in the present study provides complementary information to that from the hand-held dynamometer test, and the clinical test developed by this study may be a useful tool to evaluate GM function.

\section{CONCLUSIONS}

The present study demonstrated that the GM Clinical Test has a weak correlation with the isometric hip abductor torque test using a hand-held dynamometer. Both testing methods were reliable and repeatable between and within examiners. In addition, reference values were obtained for youth athletes. The clinical test developed in this study is a reliable, useful and low-cost method that can be included in evaluation and re-evaluation of the GM.

\section{CONFLICTS OF INTEREST}

The authors have no conflicts of interest to declare.

Submitted: April 20, 2020 CDT, Accepted: September 20, 2020

CDT 


\section{REFERENCES}

1. Ferber R, Davis IM, Williams DS III. Gender differences in lower extremity mechanics during running. Clin Biomech. 2003;18(4):350-357. doi:10.10 16/s0268-0033(03)00025-1

2. Dix J, Marsh S, Dingenen B, et al. The relationship between hip muscle strength and dynamic knee valgus in asymptomatic females: A systematic review. Phys Ther Sport. 2018;S1466-853X(17):30358-30359.

3. Schmidt E, Harris-Hayes M, Salsich GB. Dynamic knee valgus kinematics and their relationship to pain in women with patellofemoral pain compared to women with chronic hip joint pain. J Sport Health Sci. 2019;8(5):486-493. doi:10.1016/i.jshs.2017.08.001

4. Ackland DC, Denton M, Schache AG, Pandy MG, Crossley KM. Hip abductor muscle volumes are smaller in individuals affected by patellofemoral joint osteoarthritis. Osteoarthr Cartil. 2019;27(2):266-272. doi:10.1016/i.joca.2018.09.013

5. Maia MS, Carandina MHF, Santos MB, Cohen M. Associação do valgo dinâmico do joelho no teste de descida de degrau com a amplitude de rotação medial do quadril. Rev Bras Med Esp. 2012;18(3):164-166. do i:10.1590/s1517-86922012000300005

6. Nakagawa TH, Moriya ÉTU, Maciel CD, SerrãO FV. Trunk, pelvis, hip and knee kinematics, hip strength, and gluteal muscle activation during a single-leg squat in males and females with and without patellofemoral pain syndrome. J Ortho Sports Phys Ther. 2012;42(6):491-501. doi:10.2519/jospt.2012.398 $\underline{7}$

7. Mclean SG, Fellin RE, Suedekum N, Calabrese G, Passerallo A, Joy S. Impact of fatigue on gender-based high-risk landing strategies. Med Sci Sports Exerc. 2007;39(3):502-514. doi:10.1249/mss.0b013e3180d47 $\underline{\mathrm{fO}}$

8. Geiser CF, O'Connor KM, Earl JE. Effects of isolated hip abductor fatigue on frontal plane knee mechanics. Med Sci Sports Exerc. 2010;42(3):535-545. doi:10.1249/mss.0b013e3181b7b227

9. Stark T, Walker B, Phillips JK, Fejer R, Beck R. Hand-held dynamometry correlation with the gold standard isokinetic dynamometry: A systematic review. $P M \& R$. 2011;3(5):472-479. doi:10.1016/i.pmr j.2010.10.025

10. Jaramillo J, Worrell TW, Ingersoll CD. Hip isometric strength following knee surgery. J Orthop Sports Phys Ther. 1994;20(3):160-165. doi:10.2519/jos pt.1994.20.3.160
11. Neal BS, Lack SM, Lankhorst NE, Raye A, Morrissey D, Middelkoop MV. Risk factors for patellofemoral pain: A systematic review and metaanalysis. Br J Sports Med. 2018;0:1-13. doi:10.1136/bjs ports-2018-099334.7

12. Bittencourt NFN, Ocarino JM, Mendonça LD, Hewett TE, Fonseca ST. Foot and hip contributions to high frontal plane knee projection angle in athletes: A classification and regression tree approach. $J$ Orthop Sports Phys Ther. 2012;42(12):996-1004. doi:1 $\underline{0.2519 / j o s p t .2012 .4041}$

13. Widler KS, Glatthorn JF, Bizzini M, et al. Assessment of hip abductor muscle strength. A validity and reliability study. J Bone Joint Surg Am. 2009;91(11):2666-2672. doi:10.2106/jbjs.h.01119

14. Portney LG, Watkins MP. Reliability of Measurements. In: Foundations of Clinical Research: Application to Practice. 3rd ed. Prentice Hall Health; 2009.

15. Pereira MIR, Gomes PSC. Testes de força e resistência muscular: Confiabilidade e predição de uma repetição máxima - revisão e novas evidências. Rev Bras Med Esp. 2003;9(5):325-335. doi:10.1590/s15 17-86922003000500007

16. Santos TRT, Oliveira BA, Ocarino JM, Holt KG, Fonseca ST. Effectiveness of hip muscle strengthening in patellofemoral pain syndrome patients: A systematic review. Bras J Phys Ther. 2015;19(3):167-176. doi:10.1590/bjpt-rbf.2014.0089

17. Paulo AC, Tavares LD, Cardoso RK, Lamas L, Pivetti B, Tricoli V. Influência do nível de força máxima na produção e manutenção da potência muscular. Rev Bras Med Esp. 2010;16(6):422-426. do i:10.1590/s1517-86922010000600005

18. Cyrino ES, Silva DRP da, Cucato GG, et al. Comparison between two motor tests used for muscular strength/endurance analysis in young women. Rev Bras Cineantropom Desempenho Hum. 2013;15(3). doi:10.5007/1980-0037.2013v15n3p315

19. Freckleton G, Cook J, Pizzari T. The predictive validity of a single leg bridge test for hamstring injuries in autralian rules football players. Br J Sports Med. 2014;48(8):713-717. doi:10.1136/bjsports-201 $\underline{3-092356}$ 
20. Carvalhais VO do C, Araújo VL de, Souza TR, Gonçalves GGP, Ocarino J de M, Fonseca ST. Validity and reliability of clinical tests for assessing hip passive stiffness. Man Ther. 2011;16(3):240-245. doi:1 0.1016/j.math.2010.10.009

21. Portney LG, Watkins MP. Correlation. In: Foundations of Clinical Research: Application to Practice. 3rd ed. Prentice Hall Health; 2009.

22. Gonçalves M, Barbosa FSS. Análise de parâmetros de força e resistência dos músculos eretores da espinha lombar durante a realização de exercício isométrico em diferentes níveis de esforço. Rev Bras Med Esp. 2005;11(2):109-114. doi:10.1590/s1517-8692 $\underline{2005000200003}$

23. Prins MR, Van Der Wurff P. Females with patellofemoral pain syndrome have weak hip muscles: A systematic review. Aust J Phys. 2009;55(1):9-15.
24. Van Cant J, Pitance L, Feipel V. Hip abductor, trunk extensor and ankle plantar flexor endurance in females with and without patellofemoral pain. J Back Musculoskelet Rehabil. 2017;30(2):299-307. doi:10.323 3/BMR-150505

25. Ortiz A, Olson SL, Etnyre B, Trudelle-Jackson EE, Bartlett W, Venegas-Rios HL. Fatigue effects on knee joint stability during two jump tasks in women. $J$ Strength Cond Res. 2010;24(4):1019-1027. doi:10.151 9/jsc.0b013e3181c7c5d4

26. Karavirta L, Häkkinen K, Kauhanen A, et al. Individual responses to combined endurance and strength training in older adults. MedSci Sports Exerc. 2011;43(3):484-490. doi:10.1249/mss.0b013e3181f1bf $\underline{0 \mathrm{~d}}$

27. Gandevia SC. Neural control in human muscle fatigue: Changes in muscle afferents, motoneurones and motor cortical drive. Acta Physiol Scand. 1998;162(3):275-283. doi:10.1046/j.1365-201x.1998.0 299f.x 